\title{
Effect of Autoclave Curing on the Microstructure of Blended Cement Mixture Incorporating Ground Dune Sand and Ground Granulated Blast Furnace Slag
}

\author{
Omer Abdalla Alawad ${ }^{1,2), *}$, Abdulrahman Alhozaimy ${ }^{1)}$, Mohd Saleh Jaafar²), \\ Farah Nora Abdul Aziz ${ }^{2)}$, and Abdulaziz Al-Negheimish ${ }^{1)}$
}

(Received June 7, 2014, Accepted July 19, 2015, Published online August 12, 2015)

\begin{abstract}
Investigating the microstructure of hardened cement mixtures with the aid of advanced technology will help the concrete industry to develop appropriate binders for durable building materials. In this paper, morphological, mineralogical and thermogravimetric analyses of autoclave-cured mixtures incorporating ground dune sand and ground granulated blast furnace slag as partial cementing materials were investigated. The microstructure analyses of hydrated products were conducted using scanning electron microscopy (SEM), energy dispersive X-ray spectroscopy (EDX), differential thermal analysis (DTA), thermo-graphic analysis (TGA) and X-ray diffraction (XRD). The SEM and EDX results demonstrated the formation of thin plate-like calcium silicate hydrate plates and a compacted microstructure. The DTA and TGA analyses revealed that the calcium hydroxide generated from the hydration binder materials was consumed during the secondary pozzolanic reaction. Residual crystalline silica was observed from the XRD analysis of all of the blended mixtures, indicating the presence of excess silica. A good correlation was observed between the compressive strength of the blended mixtures and the $\mathrm{CaO} / \mathrm{SiO}_{2}$ ratio of the binder materials.
\end{abstract}

Keywords: ground dune sand, slag, autoclave curing, SEM, EDX, DTA, TGA, XRD.

\section{Introduction}

Concrete is a composite material consisting of aggregate, water and Portland cement (PC). When PC is placed in contact with water, several chemical reactions occur (Hewlett 2003; Taylor 1997). These reactions produce many phases, such as calcium silicate hydrates $(\mathrm{C}-\mathrm{S}-\mathrm{H}$ gel $)$, calcium hydroxide ( $\mathrm{CH}$ or portlandite), ettringite (AFt), and monasulfomonite (AFm) (Englehardt and Peng 1995; Hewlett 2003). To ensure the continuity of cement hydration, the cast mixture should be cured under appropriate conditions (Mehta and Monteiro 2006; Topçu and Uygunoğlu 2007). The typical curing conditions used in concrete technology include normal curing, low pressure steacuring, high pressure steam curing and membrane curing. The socalled normal curing is conducted under a moist and ambient temperature. Under these conditions, the hydration process and strength development rate of cement paste are slow (Liu

\footnotetext{
${ }^{1)}$ Civil Engineering Department and Center of Excellence for Concrete Research and Testing, College of Engineering, King Saud University, Riyadh, Saudi Arabia.

*Corresponding Author; E-mail: oalawad@ksu.edu.sa ${ }^{2)}$ Civil Engineering Department, Faculty of Engineering, Universiti Putra Malaysia, Seri Kembangan, Malaysia.

Copyright ( $\odot$ The Author(s) 2015. This article is published with open access at Springerlink.com
}

et al. 2005). Consequently, concrete takes several days, or sometimes several months, to reach its ultimate strength (Gutteridge and Dalziel 1990; Topçu and Uygunoğlu 2007). As a result, in precast concrete plants and other applications where higher early strength is of great concern, normal curing conditions are not preferred (Erdoğdu and Kurbetci 2005; Hanson 1963; Kołakowski et al. 1994).

In precast concrete technology, accelerated curing conditions, such as high-pressure steam curing (autoclave curing), are adopted (Mindess et al. 1981). The advantages of autoclave curing include that compressive strength equivalent to that of 28 days of normal curing can be achieved within $24 \mathrm{~h}$ under autoclave curing, less drying shrinkage, elimination of efflorescence, and better resistance to sulfate attacks (Kołakowski et al. 1994; Menzel 1934; Mindess et al. 1981; Neville 1973). Another advantage of autoclave curing is that many types of siliceous materials can be used as supplementary cementing materials even though some siliceous materials may not be feasible to react under normal curing conditions (Kalousek 1954).

The microstructure of cement paste cured under autoclave conditions is different than that produced at ambient temperature (Menzel 1934). The primary formed C-S-H gel converts to crystalline alpha dicalcium silicate hydrate $(\alpha-$ $\mathrm{C}_{2} \mathrm{SH}$ ) or $\mathrm{C}_{3} \mathrm{SH}_{1.5}$ (Jupe et al. 2008; Mindess et al. 1981; Taylor 1997). These phases are porous and weak, which leads to a deterioration in the compressive strength and concrete durability (Eilers et al. 1983; Grabowski and Gillott $1989)$. To avoid the formation of undesired phases $\left(\alpha-\mathrm{C}_{2} \mathrm{SH}\right.$ 
and $\mathrm{C}_{3} \mathrm{SH}_{1.5}$ ), fine siliceous material should be added at $30-40 \%$ by weight of the cement. The added siliceous materials react with the $\mathrm{CH}$ generated from the $\mathrm{PC}$ hydration to produce new $\mathrm{C}-\mathrm{S}-\mathrm{H}$ phases, such as tobermorite and xonotlite (Berardi et al. 1975; Eilers et al. 1983; Mindess et al. 1981; Taylor 1997). The hydration product features of autoclaved mixtures depend on many parameters, including the curing conditions, calcium to silica ratio $(\mathrm{Ca} / \mathrm{Si})$, and type of added silica (Bresson et al. 2002; Eilers et al. 1983; Hope 1981; Kołakowski et al. 1994). It has been stated that, under autoclave conditions, the use of crystalline silica produces high strength compared to the use of amorphous silica (Assarsson and Rydberg1956; Grabowski and Gillott 1989; Jupe et al. 2008; Luke 2004; Sanders and Smothers 1957; Yazici 2007). Additionally, it has been demonstrated that, at each autoclaving temperature, there is an optimum period of curing that results in good mechanical and physical properties (Hanson 1963; Menzel 1934; Neville 1973; Shi and $\mathrm{Hu}$ 2003; Yaz1c1 et al. 2008).

Recently, many tools have been used to examine the concrete structure not only at microscale but also at the nano-level (Chae et al. 2013; Kar et al. 2014). Scanning electron microscopy (SEM), energy dispersive X-ray spectroscopy (EDX), X-ray diffraction (XRD) and thermo-graphic analysis (DTA and TGA) are being used to study the microscale changes that occur in the cement paste and concrete structure (Murmu and Singh 2014; Singh et al. 2015). Understanding the hydration mechanism and microstructure properties with the aid of advanced technology will help the concrete industry develop appropriate binders for durable building materials (Lange et al. 1997).

Previous studies by the authors have reported that ground dune sand and ground granulated blast furnace can be used as high volume cement replacement materials in autoclave concrete production (Alawad et al. 2015). However, the effect of autoclave conditions on microstructure of blended cement mixtures containing ground dune sand and slag have not been studied in depth. This study aimed to investigate the microstructures of autoclave-cured products of blended cement paste mixtures that incorporate ground dune sand and ground granulated blast furnace slag as cement replacement materials. Microstructure analyses were performed using SEM, EDX, XRD, DTA, and TGA.

\section{Experimental Work}

\subsection{Raw Material}

PC complying with ASTM C 150 and ground granulated blast furnace slag of grade 100 (ASTM C 989) were used in this study. The chemical composition and physical properties of the PC and slag are presented in Table 1. The dune sand used in this study was obtained from Riyadh, Saudi Arabia. The particle size analysis of natural dune sand is shown in Fig. 1. The natural dune sand was mechanically ground until $95 \%$ passed a $45-\mu \mathrm{m}$ sieve. The chemical composition and specific surface area of the ground dune sand (GDS) are presented in Table 1. The XRD patterns and SEM images of the GDS and slag are shown in Figs. 2 and 3, respectively.

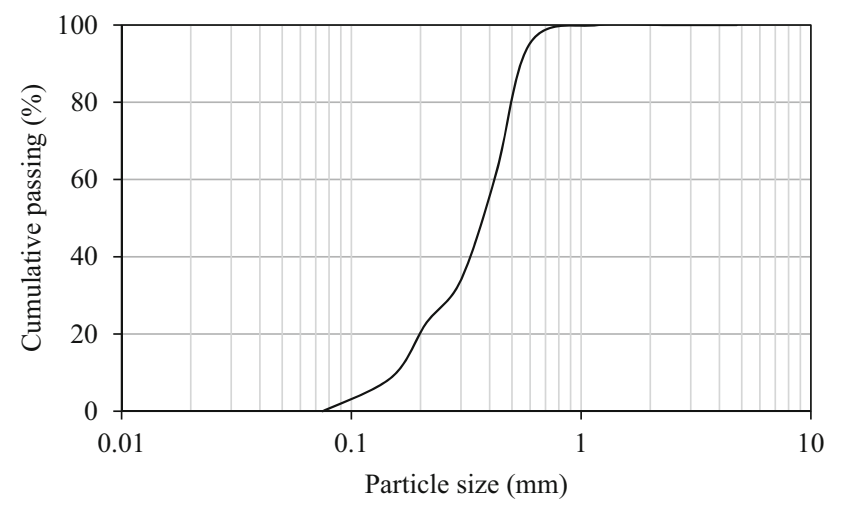

Fig. 1 Particle size distribution of natural dune sand.

Table 1 Chemical and physical properties of PC, GDS and Slag.

\begin{tabular}{c|c|c|c}
\hline \multirow{2}{*}{ Chemical oxide } & \multicolumn{3}{|c}{ Chemical composition (\%) } \\
\cline { 2 - 4 } & PC & GDS & Slag \\
\hline $\mathrm{SiO}_{2}$ & 22.62 & 93.4 & 13.74 \\
\hline $\mathrm{Al}_{2} \mathrm{O}_{3}$ & 6.11 & 0.19 & 0.44 \\
\hline $\mathrm{Fe}_{2} \mathrm{O}_{3}$ & 3.69 & 0.32 & 43.1 \\
\hline $\mathrm{CaO}$ & 57.96 & 0.45 & 5.76 \\
\hline $\mathrm{MgO}$ & 2.16 & - & 0.41 \\
\hline $\mathrm{K}_{2} \mathrm{O}$ & 0.98 & 0.04 & 0.2 \\
\hline $\mathrm{Na}_{2} \mathrm{O}$ & 0.17 & - & 1.89 \\
\hline $\mathrm{SO}$ & 2.99 & - & 1.34 \\
\hline LOI & 3.02 & 1.15 & 5314 \\
\hline Specific surface area, BET cm & & \\
\hline Specific gravity & 3012 & 2574 & 2.94 \\
\hline
\end{tabular}



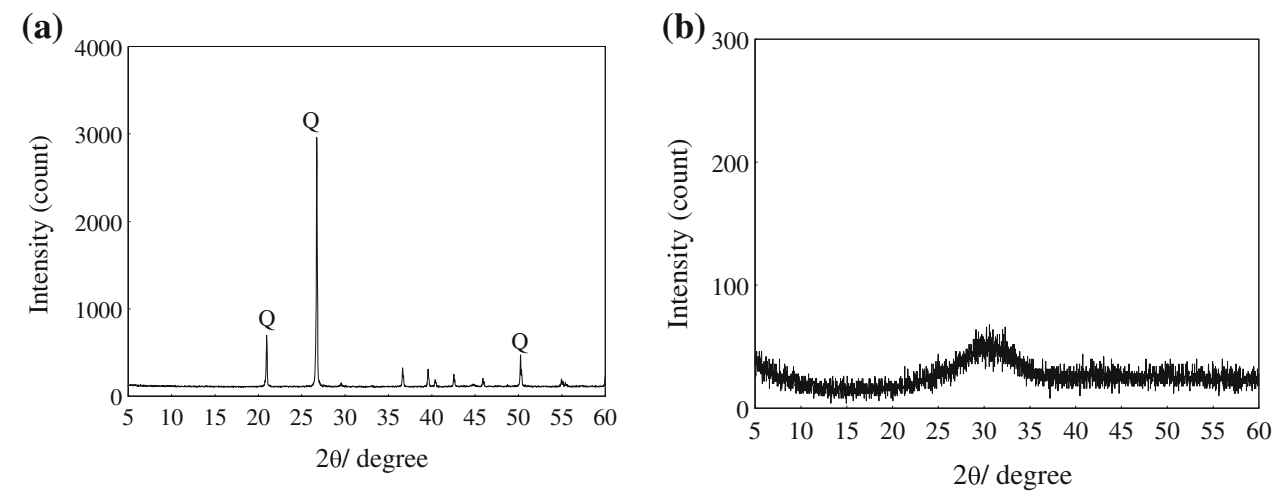

Fig. 2 XRD pattern a GDS and b slag.
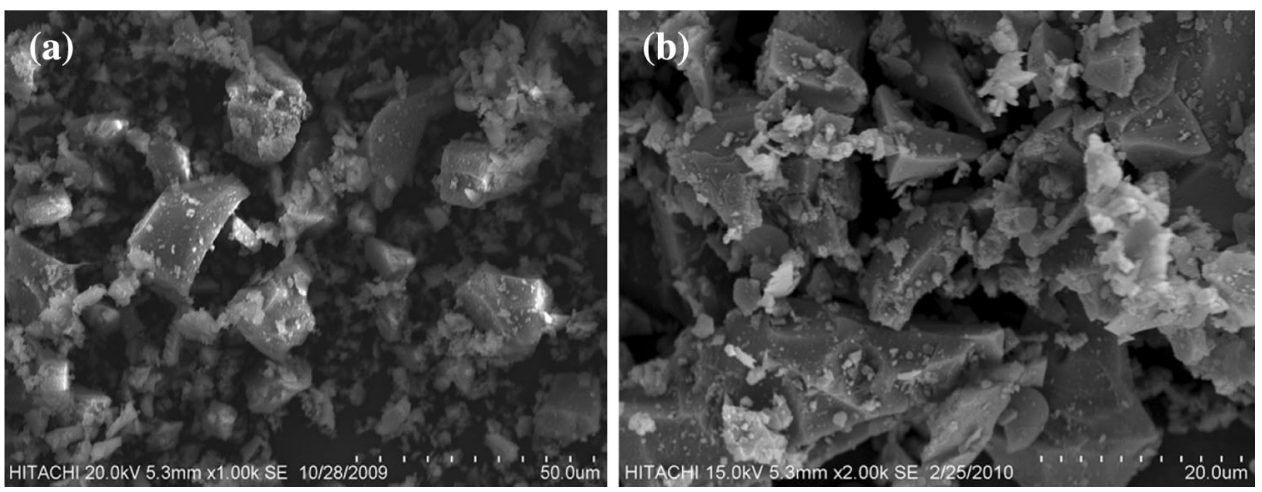

Fig. 3 SEM images a GDS and b slag.

As shown in Fig. 2a, a very sharp quartz peak at $26.5^{\circ}(2 \theta)$ reflecting the crystallinity of silica in the GDS was observed. However, no stand-out peak of the slag was detected, representing the non-crystallinity of slag (Fig. 2b) (Divsholi et al. 2014). The SEM of GDS and slag presented that both materials have an angular particle texture (Fig. 3). Mining sand with a maximum particle size of $2.36 \mathrm{~mm}$ was used as a fine aggregate to fabricate mortar mixtures. The specific gravity and fineness modulus of the fine aggregate were 2.5 and 2.49 , respectively.

\subsection{Sample Preparation}

Five mixtures of paste, a control mixture and four blended mixtures, were prepared. The control mixture (M1) consisted of $100 \%$ PC as the binder material. For the blended mixtures, GDS and slag were incorporated as PC replacement materials. The replacement level of GDS was held constant at $40 \%$, while the concentrations of slag were $0,15,30$, and $45 \%$. The blended mixtures were denoted as M2, M3, M4, and M5, and their binder composition details are summarized in Table 2. To examine the performance of the GDS and slag with regard to compressive strength, the control and the four blended mortar mixtures were formulated with a binder composition similar to that used for paste mixtures. The mortar had a binder:fine aggregate:water ratio of 1:3:0.3.

The paste and mortar mixtures were prepared according to ASTM C 305 and cast in $50 \mathrm{~mm}$ cubic steel molds. The cast samples were covered with plastic sheets and kept under laboratory conditions $\left(23 \pm 3{ }^{\circ} \mathrm{C}\right.$ and $50 \pm 5$ relative humidity) for $24 \mathrm{~h}$. After being demolded at the age of $24 \mathrm{~h}$, the samples were immersed in water at $23 \pm 3{ }^{\circ} \mathrm{C}$ (normal curing conditions) for $16 \mathrm{~h}$ to develop initial strength and then placed in the autoclave chamber. The chamber

Table 2 Binder proportions for the ternary blended cement mixtures.

\begin{tabular}{c|c|c|c|c|c}
\hline \multirow{2}{*}{ Mixture ID } & \multicolumn{3}{|c|}{ Ingredient \% } & Water/binder ratio & \multirow{2}{*}{$\mathrm{Molar} \mathrm{CaO} / \mathrm{SiO}_{2}$} \\
\cline { 2 - 6 } & PC & GDS & Slag & 0.5 & 2.75 \\
\hline \hline M1 & 100 & - & - & 0.5 & 0.74 \\
\hline M2 & 60 & 40 & 15 & 0.5 & 0.67 \\
\hline M3 & 45 & 40 & 30 & 0.5 & 0.61 \\
\hline M4 & 30 & 40 & 45 & 0.5 & 0.56 \\
\hline
\end{tabular}



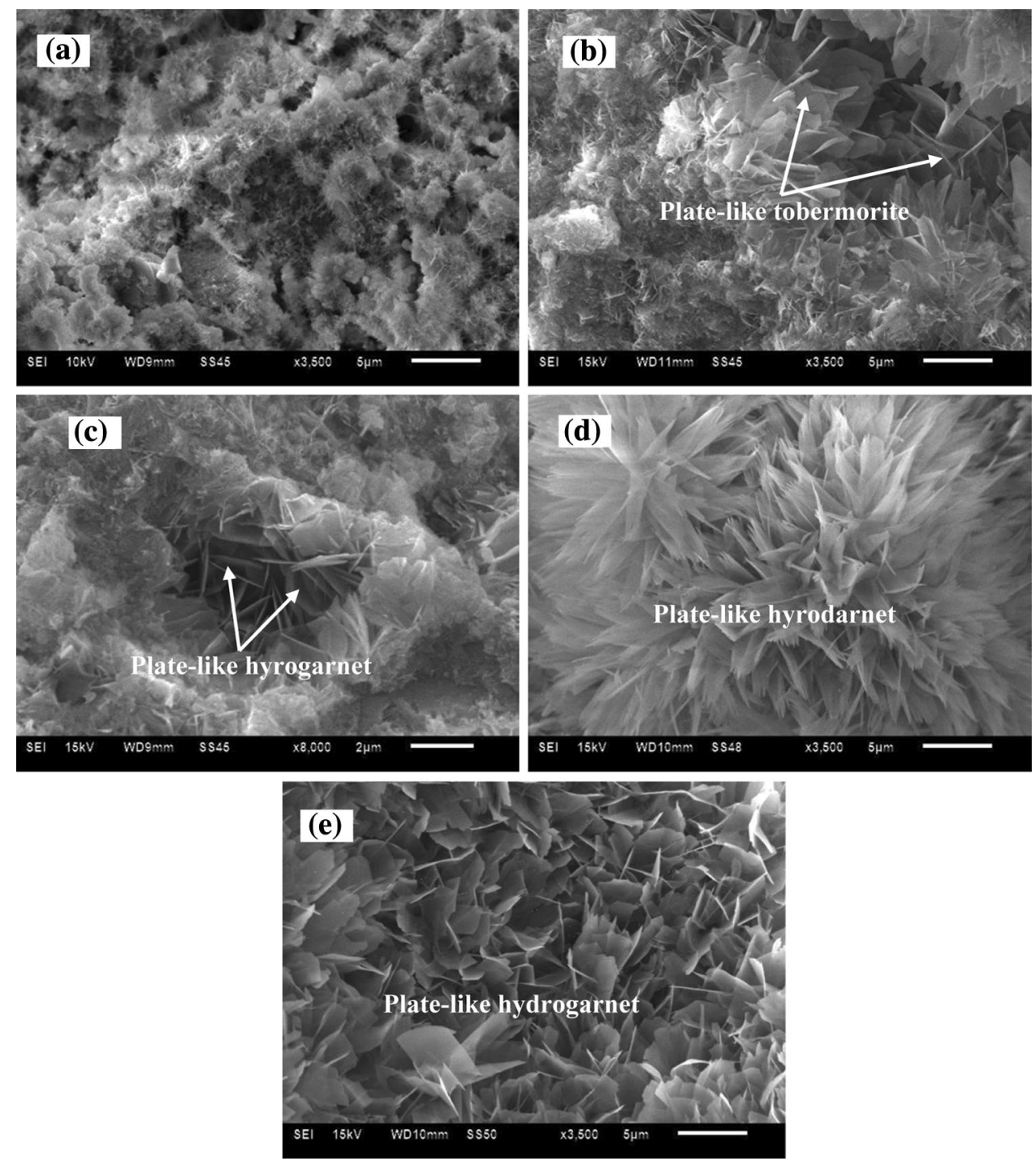

Fig. 4 SEM images of autoclave cured mixtures a M1, b M2, c M3, d M4 and e M5.

temperature was increased from room temperature to $182 \pm 3{ }^{\circ} \mathrm{C}$ within $1 \mathrm{~h}$. Consequently, the pressure was increased from atmospheric pressure to $1.0 \mathrm{MPa}$. The adopted autoclave conditions (temperature and pressure) are similar to those used by Yang et al. (2000). The temperature and pressure were kept constant at $182 \pm 3{ }^{\circ} \mathrm{C}$ and $1.0 \mathrm{MPa}$ for $5 \mathrm{~h}$, then the autoclave heater was turned off and the chamber was allowed to cool naturally. Room temperature was reached in approximately $1.5 \mathrm{~h}$.

\subsection{Sample Characterization}

Microstructural and microanalytical characterizations of the hydrated pastes were conducted using a Jeol JSM 6610LV coupled with EDX. The samples for SEM analysis were prepared by taking fractured surface specimens of the cured pastes. The specimens were glued to carbon stubs with carbon paint prior to the SEM analysis. The SEM analysis was carried out using accelerating voltages of 10 and $15 \mathrm{kV}$ and magnifications of $\times 3500$ and $\times 8000$. The chemical composition analysis of selected spots (fields of view) was carried out using EDX.

Thermogravimetric analysis (DTA and TGA) was carried out using a TA instrument (model SDT Q600). DTA and
TGA analyses were conducted to monitor the phase changes and to evaluate the amount of $\mathrm{CH}$ consumed in the cured samples. A predefined amount of the selected sample in powder form was weighed, placed in a platinum sample pan and then heated from room temperature to $1000{ }^{\circ} \mathrm{C}$ at a heating rate of $10{ }^{\circ} \mathrm{C} \mathrm{min}{ }^{-1}$ in a nitrogen gas flow. XRD analysis was conducted using a Shimadzu XRD-6000 diffractometer with a scanning rate of $2^{\circ} / \mathrm{min}$ from $10^{\circ}$ to $60^{\circ}$ (20) to obtain the mineralogical information for each sample. The samples for XRD analysis were prepared by grinding pieces of hydrated pastes into a powder form that could pass a $75-\mu \mathrm{m}$ sieve. The compressive strength test of the cast mortars was carried out in accordance with ASTM C109.

\section{Results and Discussion}

\subsection{Morphological Study}

The SEM images and EDX analyses of the hardened pastes of the control and blended mixtures cured under autoclave conditions are shown in Figs. 4 and 5, respectively. Fibrouslike hydrated products and pores of a dark color were 

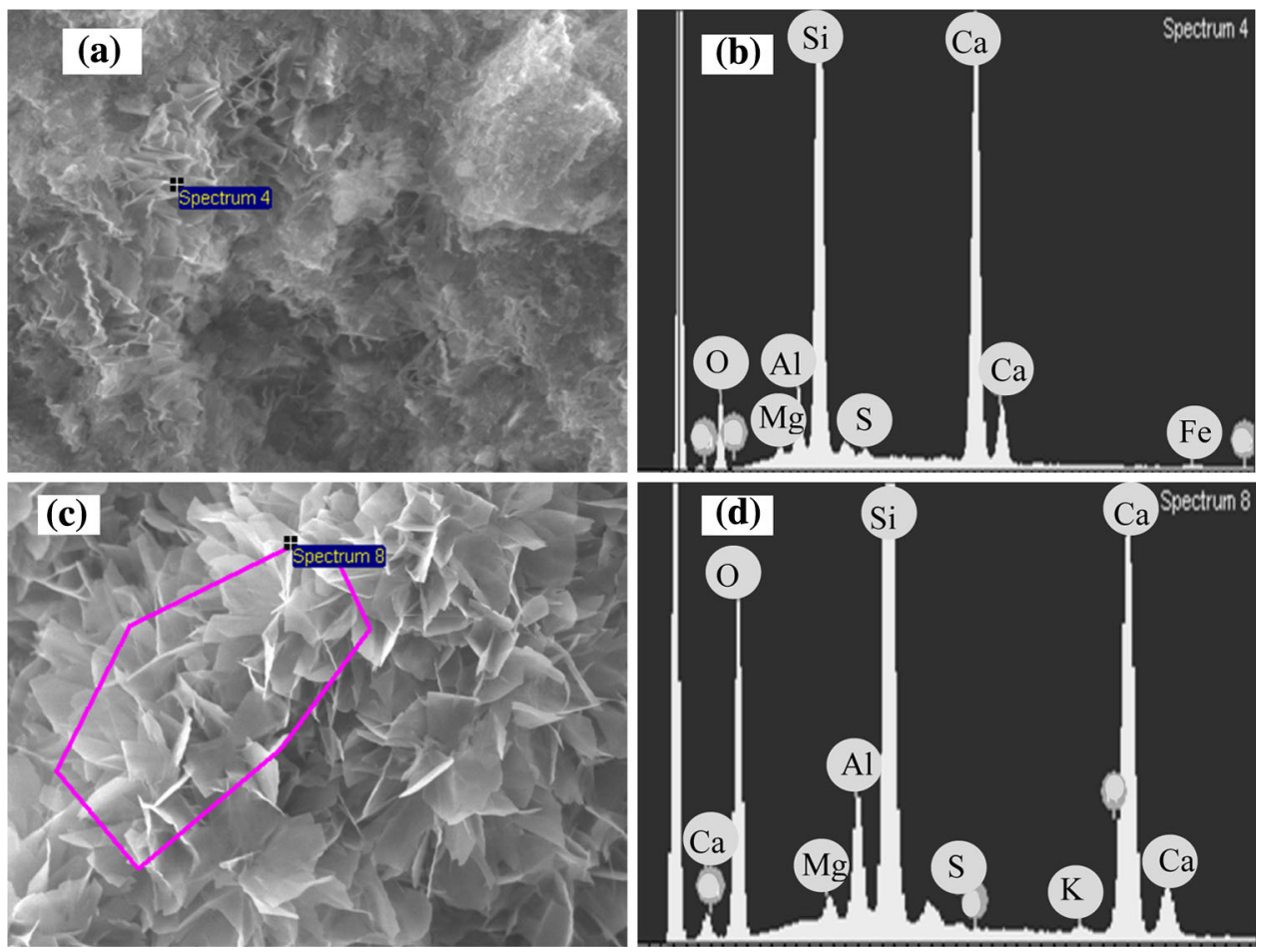

Fig. 5 EDX analysis of M2 and M4 mixtures.

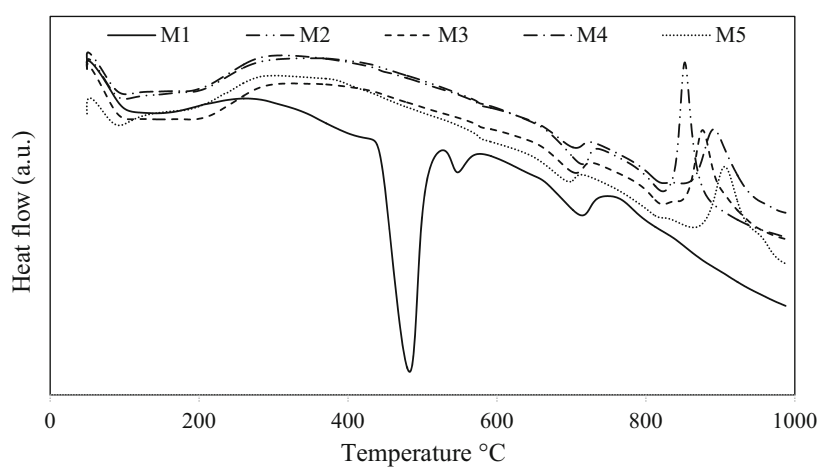

Fig. 6 DTA curves of autoclave cured mixtures.

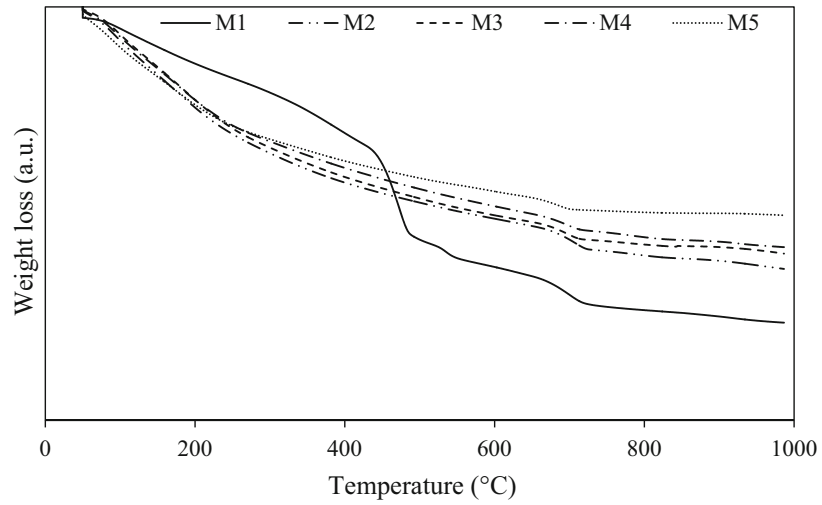

Fig. 7 TGA curves of autoclave cured mixtures.

observed in the control mixture (Fig. 4a). This image also revealed that the hydrated products are associated with loose structures. These features explained the negative effect of the performance of the plain cement mixture cured under autoclave conditions (Alawad et al. 2014; Bakharev et al. 1999;

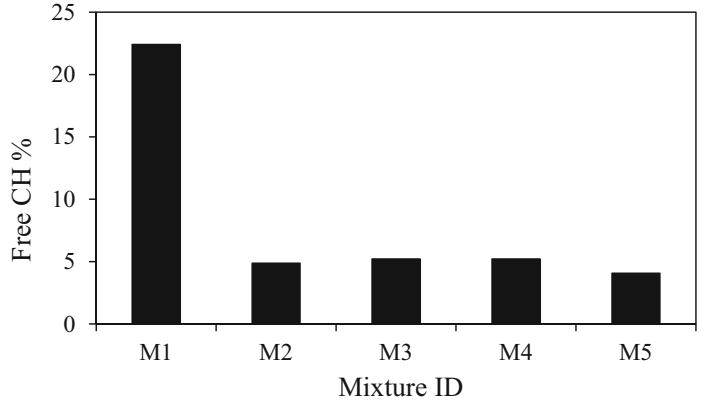

Fig. 8 Free $\mathrm{CH}$ of autoclave cured mixtures.

Kjellsen et al. 1991). For the M2 mixture, plate-like structures of tobermorite $\left(\mathrm{C}_{5} \mathrm{~S}_{6} \mathrm{H}_{5}\right)$ with dense and closed network structures were observed, as shown in Fig. 4b. For the blended mixtures containing slag (M3, M4 and M5), plate-like structures of tobermorite $\left(\mathrm{C}_{5} \mathrm{~S}_{6} \mathrm{H}_{5}\right)$ and hydrogarnet $\left(\mathrm{C}_{4} \mathrm{ASH}_{4}\right)$ were observed, as shown in Fig. 4c-e (Klimesch and Ray 1998; Kyritsis et al. 2009). The hydrogarnet phases were dominant when the content of slag was increased. In particular, thin plate-like structures with broken edges were observed in the M4 mixture. In general, the blended mixtures revealed dense, compacted and closed network structures. This structure justified the enhancement effect in the compressive strength of the blended mixtures cured under autoclave conditions (Kondo et al. 1975; Wongkeo et al. 2012).

Figure 5 presents the EDX analysis of the M2-AC and M4-AC mixtures. The image and EDX analysis of the M2$\mathrm{AC}$ mixture are shown in Fig. 5a and b, respectively. High peak intensities of $\mathrm{Ca}$ and $\mathrm{Si}$ with a $\mathrm{Ca} / \mathrm{Si}$ ratio approximately equal to unity were observed from the EDX analysis (Fig. 5b). This analysis indicated that the crystalline 
structure phases are newly formed CSH (i.e., tobermorite). The formation of $\mathrm{CSH}$ phases with a $\mathrm{Ca} / \mathrm{Si}$ ratio close to unity is a favored result for the concrete strength and physical properties (Eilers et al. 1983; Yazic1 et al. 2008). The image and EDX analysis of the M4-AC mixture are shown in Fig. 5c and d, respectively. The presence of slag leads to the formation of thin crystalline structure phases of newly formed aluminum bearing $\mathrm{CSAH}$ (i.e., $\mathrm{C}_{4} \mathrm{SAH}_{4}$ ) (Klimesch and Ray 1998; Kyritsis et al. 2009; Mostafa et al. 2009). The reason for the formation of $\mathrm{C}_{4} \mathrm{SAH}_{4}$ phases is attributed to the presence of the element $\mathrm{Al}$ in the system as the slag contains a significant amount of $\mathrm{Al}_{2} \mathrm{O}_{3}$ (Table 1). The EDX analysis indicated that the presence of GDS and slag not only prevented the formation of weak and permeable phases $\left(\alpha-\mathrm{C}_{2} \mathrm{SH}\right)$ but also introduced new $\mathrm{CSH}$ phases, such as tobermorite $\left(\mathrm{C}_{5} \mathrm{~S}_{6} \mathrm{H}_{5}\right)$ and hydrogarnet $\left(\mathrm{C}_{4} \mathrm{SAH}_{4}\right)$, which are associated with high strength and low permeability (Yazıcı et al. 2008).

\subsection{Thermogravimetric Analysis}

Figures 6 and 7 show the DTA and TGA curves of the control and blended mixtures cured under autoclave conditions. The DTA curve of the M1 mixture revealed the existence of a clear endothermic peak located between 450 and $550{ }^{\circ} \mathrm{C}$ (Fig. 6). This endothermic peak was attributed to the de-hydroxylation of $\mathrm{CH}$ generated from the $\mathrm{PC}$ hydration (Alarcon-Ruiz et al. 2005; Oner and Akyuz 2007). For the blended mixture containing $40 \%$ GDS (M2), no endothermic peak in the $\mathrm{CH}$ zone was observed, indicating the consumption of $\mathrm{CH}$ in the secondary pozzolanic reaction between the $\mathrm{SiO}_{2}$ of GDS and the $\mathrm{CH}$ generated from the PC. Additionally, a significant exothermic peak at $850{ }^{\circ} \mathrm{C}$, due to the crystallization of $\mathrm{CSH}$ and belite, was observed in the M2 mixtures (Klimesch et al. 1996). For ternary blended mixtures (M3-M5), no endothermic peak in the $\mathrm{CH}$ zone was observed, and the clear formation of an exothermic peak at $850{ }^{\circ} \mathrm{C}$, due to the crystallization of $\mathrm{CSH}$, was instead observed. However, the intensity of the exothermic peaks at $850{ }^{\circ} \mathrm{C}$ of the slag mixtures were less than that of the M2 mixture (PC-GDS). It was also observed that all the tested mixtures exhibit an endothermic peak at $750{ }^{\circ} \mathrm{C}$ (Fig. 6). This endothermic peak was ascribed to carbonation that may take place during sample preparation (Saikia et al. 2006).

Figure 7 shows the TGA curves for the control and blended mixtures cured under autoclave conditions. With respect to the $\mathrm{CH}$ change, which occurred between 450 and
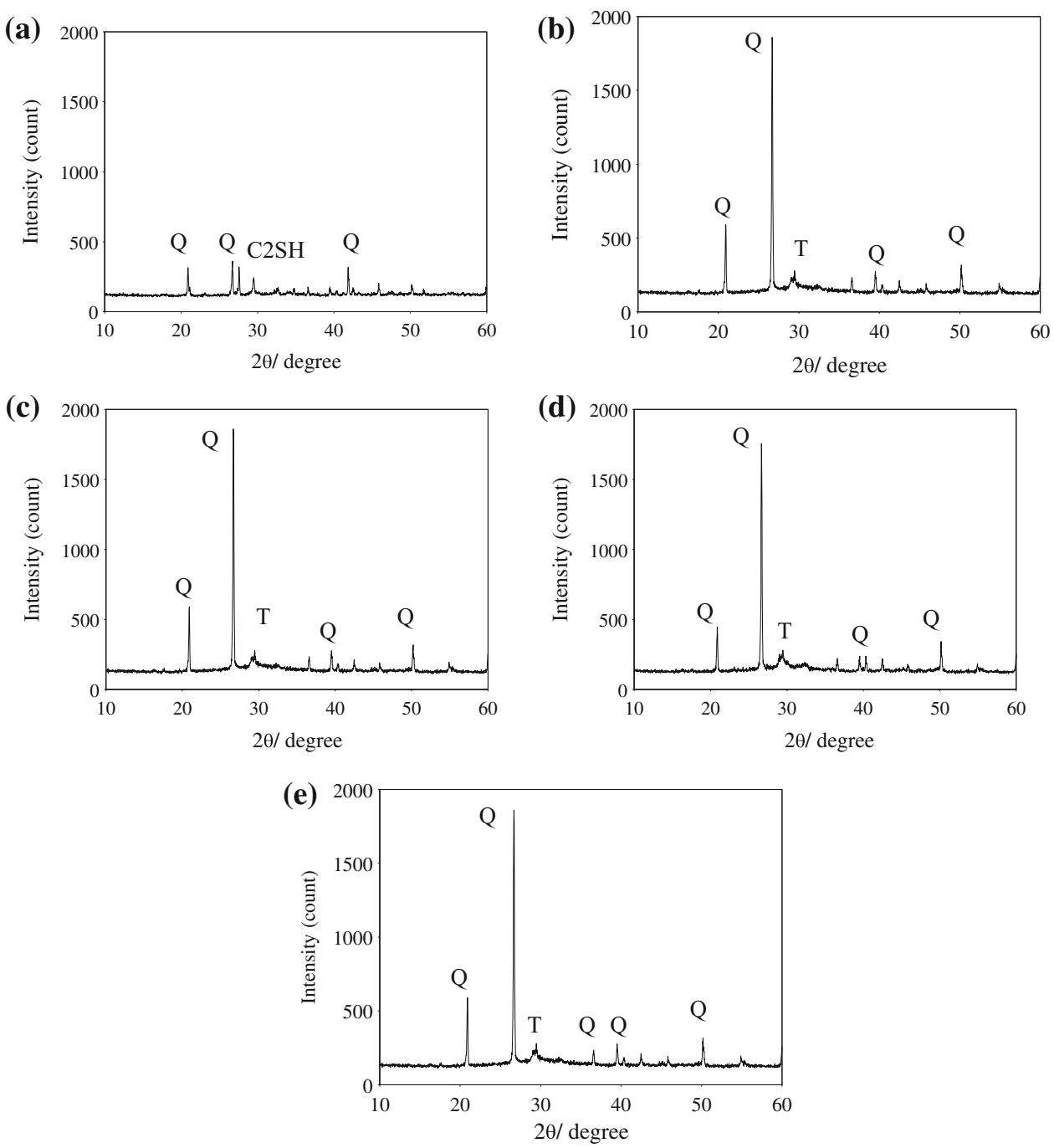

Fig. 9 XRD patterns of autoclave cured mixtures a M1, b M2, c M3, d M4 and e M5. 


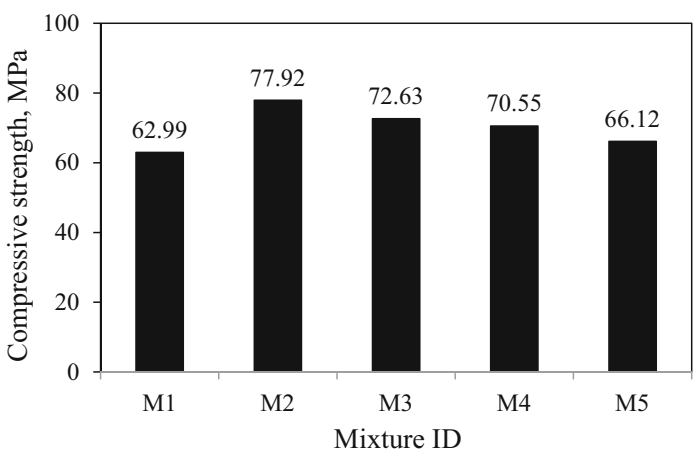

Fig. 10 Compressive strengths of autoclave cured mixtures.

$550{ }^{\circ} \mathrm{C}$, an obvious mass loss in M1 was observed, while all the blended samples showed less mass change in this zone. The calculated value of free $\mathrm{CH}$ of $\mathrm{M} 1$ was found to be $22.4 \%$, whereas, for the blended mixtures (M2-M5), it was found to be approximately $5 \%$, irrespective of the slag content, as shown in Fig. 8. The low mass change in the blended mixtures is evidence of the consumption of $\mathrm{CH}$ in the newly formed $\mathrm{CSH}$ phases, such as tobermorite.

\subsection{Mineralogical Analysis}

The XRD patterns of the control and blended mixtures cured under autoclave conditions are shown in Fig. 9. For the M1 mixture, a crystalline peak at $29.5^{\circ}-31^{\circ}(2 \theta)$ corresponding to the $\alpha$-dicalcium silicate hydrate $\left(\alpha-\mathrm{C}_{2} \mathrm{SH}\right)$ was observed, as shown in Fig. 9a. This peak might overlap with the calcite peak that took place during the sample curing and preparation. Although the thermogravimetric analysis indicated the presence of $\mathrm{CH}$ (portlandite), no portlandite peaks were observed from the XRD of M1. The observed nonconsistency in thermogravimetric and XRD results could be attributed to the phenomenon of preferential orientation exhibited by portlandite crystals during XRD (Wee et al. 2000). For $M 2$, residual quartz peaks at $2 \theta^{\circ}=21^{\circ}$ and $26.5^{\circ}$ were detected, but no portlandite peaks were observed, as shown in Fig. 9b. These residual quartz peaks (1890 count) indicated the presence of excess crystalline silica in the M2 mixture. For the M3, M4 and M5 mixtures, the incorporation of slag as a ternary blended element did not consume the remaining crystalline silica, as shown in Fig. 9c-e. The quartz peak intensities for the M3, M4 and M5 mixtures at $26.5^{\circ}$ were 1900,1880 and 1910 counts, respectively. The results indicated that the reactivity of slag is greater than that of GDS (Kondo et al. 1975). Consequently, the $\mathrm{CaO}$ provided from the slag reacted rapidly with the $\mathrm{SiO}_{2}$ and $\mathrm{Al}_{2} \mathrm{O}_{3}$ generated from the slag itself, resulting in there being no free $\mathrm{CaO}$ to combine with the un-reacted crystalline silica of GDS. Therefore, to utilize the excess crystalline silica, materials rich in $\mathrm{CaO}$ should be added.

\subsection{Compressive Strength}

The compressive strengths of the control and blended mixtures (M1-M5) cured under autoclave conditions are shown in Fig. 10. The compressive strength results presented are an average of three samples. The average of the strength

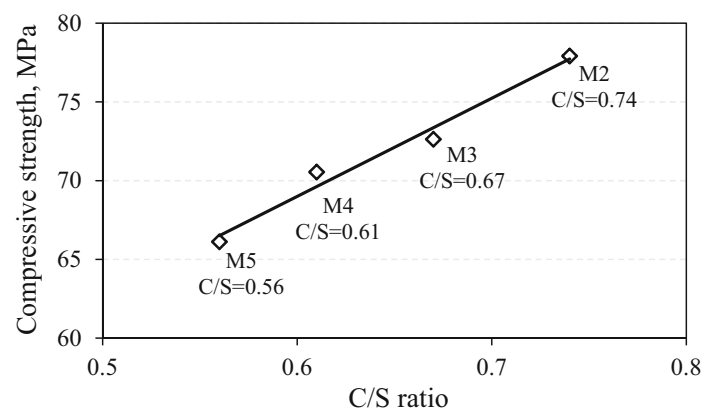

Fig. 11 Correlation of compressive strength and molar $\mathrm{CaO} /$ $\mathrm{SiO}_{2}$ ratio (C/S).

values of the three samples is within the limits of $5 \%$. As can be observed from Fig. 10, all the blended mixtures yielded compressive strengths higher than that of the control (M1). The low compressive strength of M1 is attributed to the formation of lime-rich alpha dicalcium silicate hydrate $\left(\alpha-\mathrm{C}_{2} \mathrm{SH}\right)$ (Bakharev et al. 1999; Kjellsen et al. 1991). The microstructure analysis of M1 showed the formation of fibrous-like hydrated products and loose structures. These features explained the negative effect of autoclave curing on the compressive strength performance of the control mixture. The inclusion of $40 \%$ GDS enhanced the compressive strength of M2 by approximately $16 \%$ compared to that of M1. The enhancement in the compressive strength could be ascribed to the fact that, under autoclave curing, the $\mathrm{SiO}_{2}$ of GDS reacted with the calcium hydroxide $(\mathrm{CH})$ liberated from the hydration of the cement to form additional $\mathrm{CSH}$ phases, such as tobermorite $\left(\mathrm{C}_{5} \mathrm{~S}_{6} \mathrm{H}_{5}\right)$. The formation of tobermorite filled the pores and enhanced the compactness of the hydrated mixture. It has been reported that tobermorite is associated with high strength and lower permeability features (Eilers et al. 1983, Jupe et al. 2008). The inclusion of slag as a further PC replacement (M3, M4 and M5) maintained the compressive strength between 66 (M1) and $72 \mathrm{MPa}$ (M2). The slight decrease in the compressive strength in comparison with $\mathrm{M} 2$ could be attributed to the formation of hydrogarnet $\left(\mathrm{C}_{4} \mathrm{ASH}_{4}\right)$ phases instead of tobermorite $\left(\mathrm{C}_{5} \mathrm{~S}_{6} \mathrm{H}_{5}\right)$. It has been stated that the performance of the mechanical properties of hydrogarnet is lower than that of tobermorite (Kondo et al. 1975). In general, the slag-bended mixtures revealed a dense, compacted and closed network of thin plate-like structures. Thin plate-like structures were formed due to the presence of the element aluminum in the system. The compressive strength result indicated that a combination of $40 \%$ GDS and $45 \%$ slag could be used to reduce the total weight of PC by up to $85 \%$ and still achieve compressive strength performance comparable to that of the control mixture (M1). It should be mentioned that a mixture containing $40 \%$ GDS and $60 \%$ slag (no cement) was not cast in this study. The literature review showed that the use of cement-less mixtures had resulted in cracking during autoclave curing (Shi and $\mathrm{Hu}$ 2003). The cracking was due to the lack of strength development, and the specimens were not strong enough to withstand the high temperature and pressure during the autoclaving process. 
Figure 11 presents the relationship between the compressive strength and molar $\mathrm{CaO} / \mathrm{SiO}_{2}$ ratio of the raw binder materials. The molar $\mathrm{CaO} / \mathrm{SiO}_{2}$ ratios of the control and blended mixtures are presented in Table 2. It was found that there is a good correlation between the compressive strength and molar $\mathrm{CaO} / \mathrm{SiO}_{2}$ ratio. The compressive strength decreases almost linearly as the $\mathrm{CaO} / \mathrm{SiO}_{2}$ ratio decreases $\left(\mathrm{R}^{2}=0.99\right)$. The literature review demonstrated that the optimum $\mathrm{CaO} / \mathrm{SiO}_{2}$ ratio for autoclave curing to achieve concrete strength is around unity (Alhozaimy et al. 2012; Eilers et al. 1983; Taylor 1997). In this study, the highest compressive strength achieved was $72 \mathrm{MPa}(\mathrm{M} 2-\mathrm{AC})$ with a $\mathrm{CaO} / \mathrm{SiO}_{2}$ ratio of 0.74 . Clearly, this value for the $\mathrm{CaO} / \mathrm{SiO}_{2}$ ratio is lower than that found in the literature. The incorporation of slag as a further PC replacement caused a further reduction in the $\mathrm{CaO} / \mathrm{SiO}_{2}$ ratio due to the low content of $\mathrm{CaO}$ in the slag compared to that of PC (Table 1). Therefore, to increase the $\mathrm{CaO} / \mathrm{SiO}_{2}$ ratio, materials rich in $\mathrm{CaO}$ content should be added.

\section{Conclusions}

This paper studied the effect of autoclave curing on the microstructure properties of mixtures incorporating GDS and ground granulated blast furnace slag as a PC replacement material. The following conclusions can be drawn:

1. The SEM and EDX results indicated that the incorporation of GDS and slag produces denser and more homogeneous microstructures. The SEM showed the clear formation of crystalline plate-like tobermorite and hydrogarnet in the blended mixture cured under autoclave conditions. In addition, the EDX indicated that the $\mathrm{CSH}$ products formed had $\mathrm{C} / \mathrm{S}$ approximately equal to unity.

2. The DTA and TGA confirmed the consumption of $\mathrm{CH}$ and clear formation of an exothermic peak at $850{ }^{\circ} \mathrm{C}$. The intensity of exothermic peaks at $850{ }^{\circ} \mathrm{C}$ of the $\mathrm{PC}$ GDS mixture (M2) was higher than those of the PCGDS-slag mixtures (M3, M4, M5).

3. The XRD indicated the presence of residual crystalline silica of the PC-GDS mixture (M2), whereas the $\mathrm{CH}$ peaks disappeared. The incorporation of slag did not affect the peak intensities of residual crystalline silica.

4. The incorporation of GDS significantly enhanced the compressive strength of the autoclave-cured mixture, whereas the inclusion of slag maintained the compressive strength to be higher or comparable to that of the control mixture.

5. A good correlation was found between the compressive strength and the $\mathrm{CaO} / \mathrm{SiO}_{2}$ ratio. The compressive strength decreased linearly as the $\mathrm{CaO} / \mathrm{SiO}_{2}$ ratio decreased. The authors recommend using materials rich in $\mathrm{CaO}$ to increase the $\mathrm{CaO} / \mathrm{SiO}_{2}$ ratio and to utilize the excess $\mathrm{SiO}_{2}$ of GDS in the pozzolanic reaction.

\section{Acknowledgments}

This study is part of a joint research project between King Saud University, Saudi Arabia and Universiti Putra Malaysia titled "Development of local sand as a cementitious material for high-performance concrete". The funding of this work by King Saud University is gratefully acknowledged.

\section{Open Access}

This article is distributed under the terms of the Creative Commons Attribution 4.0 International License (http:// creativecommons.org/licenses/by/4.0/), which permits unrestricted use, distribution, and reproduction in any medium, provided you give appropriate credit to the original author(s) and the source, provide a link to the Creative Commons license, and indicate if changes were made.

\section{References}

Alarcon-Ruiz, L., Platret, G., Massieu, E., \& Ehrlacher, A. (2005). The use of thermal analysis in assessing the effect of temperature on a cement paste. Cement and Concrete Research, 35(3), 609-613.

Alawad, O., Alhozaimy, A., Jaafar, M., Al-Negheimish, A., \& Aziz, F. (2014). Microstructure analyses of autoclaved ground dune sand-Portland cement paste. Construction and Building Materials, 65, 14-19.

Alawad, O. A., Alhoziamy, A., Jaafar, M. S., Aziz, A., Noor, F., \& Al-Negheimish, A. (2015). Blended cement containing high volume ground dune sand and ground granulated blast furnace slag for autoclave concrete industry. Applied Mechanics and Materials, 754-755(1), 395-399.

Alhozaimy, A., Al-Negheimish, A., Alawad, O., Jaafar, M., \& Noorzaei, J. (2012). Binary and ternary effects of ground dune sand and blast furnace slag on the compressive strength of mortar. Cement \& Concrete Composites, 34(6), 734-738.

Assarsson, G. O., \& Rydberg, E. (1956). Hydrothermal reactions between calcium hydroxide and amorphous silica. The Journal of Physical Chemistry, 60(4), 397-404.

Bakharev, T., Sanjayan, J., \& Cheng, Y.-B. (1999). Effect of elevated temperature curing on properties of alkali-activated slag concrete. Cement and Concrete Research, 29(10), 1619-1625.

Berardi, M. C., Chiocchio, G., \& Collepardi, M. (1975). The influence of precuring on the autoclave hydration of quartztricalcium silicate mixtures. Cement and Concrete Research, 5(5), 481-487.

Bresson, B., Meducin, F., Zanni, H., \& Noik, C. (2002). Hydration of tricalcium silicate $(\mathrm{C} 3 \mathrm{~S})$ at high temperature and high pressure. Journal of materials science, 37(24), 5355-5365.

Chae, S. R., Moon, J., Yoon, S., Bae, S., Levitz, P., Winarski, R., \& Monteiro, P. J. (2013). Advanced nanoscale 
characterization of cement based materials using X-ray synchrotron radiation: a review. International Journal of Concrete Structures and Materials, 7(2), 95-110.

Divsholi, B. S., Lim, T. Y. D., \& Teng, S. (2014). Durability properties and microstructure of ground granulated blast furnace slag cement concrete. International Journal of Concrete Structures and Materials, 8(2), 157-164.

Eilers, L. H., Nelson, E. B., \& Moran, L. K. (1983). Hightemperature cement compositions-pectolite, scawtite, truscottite, or xonotlite: Which do you want? Journal of Petroleum Technology, 35(7), 1373-1377.

Englehardt, J. D., \& Peng, C. (1995). Pozzolanic filtration/solidification of radionuclides in nuclear reactor cooling water. Waste Management, 15(8), 585-592.

Erdoğdu, Ş., \& Kurbetci, Ş. (2005). Influence of cement composition on the early age flexural strength of heat-treated mortar prisms. Cement \& Concrete Composites, 27(7), 818-822.

Grabowski, E., \& Gillott, J. (1989). Effect of replacement of silica flour with silica fume on engineering properties of oilwell cements at normal and elevated temperatures and pressures. Cement and Concrete Research, 19(3), 333-344.

Gutteridge, W. A., \& Dalziel, J. A. (1990). Filler cement: the effect of the secondary component on the hydration of Portland cement: part I. A fine non-hydraulic filler. Cement and Concrete Research, 20(5), 778-782.

Hanson, J. (1963). Optimum steam curing procedure in precasting plants. ACI Journal Proceedings, 60(1), 75-100.

Hewlett, P. (2003). Lea's chemistry of cement and concrete. Oxford, UK: Butterworth-Heinemann.

Hope, B. B. (1981). Autoclaved concrete containing flyash. Cement and Concrete Research, 11(2), 227-233.

Jupe, A. C., Wilkinson, A. P., Luke, K., \& Funkhouser, G. P. (2008). Class $\mathrm{H}$ cement hydration at $180{ }^{\circ} \mathrm{C}$ and high pressure in the presence of added silica. Cement and Concrete Research, 38(5), 660-666.

Kalousek, G. L. (1954). Studies on the cementious phases of autoclaved concrete products made of different raw materials. ACI Journal Proceedings, 50(1), 365-378.

Kar, A., Ray, I., Halabe, U. B., Unnikrishnan, A., \& DawsonAndoh, B. (2014). Characterizations and quantitative estimation of alkali-activated binder paste from microstructures. International Journal of Concrete Structures and Materials, 8(3), 213-228.

Kjellsen, K. O., Detwiler, R. J., \& Gjørv, O. E. (1991). Development of microstructures in plain cement pastes hydrated at different temperatures. Cement and Concrete Research, 21(1), 179-189.

Klimesch, D. S., \& Ray, A. (1998). Hydrogarnet formation during autoclaving at $180{ }^{\circ} \mathrm{C}$ in unstirred metakaolin-limequartz slurries. Cement and Concrete Research, 28(8), 1109-1117.

Klimesch, D. S., Ray, A., \& Sloane, B. (1996). Autoclaved cement-quartz pastes: the effects on chemical and physical properties when using ground quartz with different surface areas part I: quartz of wide particle size distribution. $\mathrm{Ce}$ ment and Concrete Research, 26(9), 1399-1408.
Kołakowski, K., De Preter, W., Van Gemert, D., Lamberts, L., \& Van Rickstal, F. (1994). Low shrinkage cement based building components. Cement and Concrete Research, 24(4), 765-775.

Kondo, R., Abo-El-Enein, S. A., \& Daimon, M. (1975). Kinetics and mechanisms of hydrothermal reaction of granulated blast furnace slag. Bulletin of the Chemical Society of Japan, 48(1), 222-226.

Kyritsis, K., Meller, N., \& Hall, C. (2009). Chemistry and morphology of hydrogarnets formed in cement based CASH hydroceramics cured at $200{ }^{\circ} \mathrm{C}$ to $350{ }^{\circ} \mathrm{C}$. Journal of the American Ceramic Society, 92(5), 1105-1111.

Lange, F., Mörtel, H., \& Rudert, V. (1997). Dense packing of cement pastes and resulting consequences on mortar properties. Cement and Concrete Research, 27(10), 1481-1488.

Liu, B., Xie, Y., \& Li, J. (2005). Influence of steam curing on the compressive strength of concrete containing supplementary cementing materials. Cement and Concrete Research, 35(5), 994-998.

Luke, K. (2004). Phase studies of pozzolanic stabilized calcium silicate hydrates at $180^{\circ} \mathrm{C}$. Cement and Concrete Research, 34(9), 1725-1732.

Mehta, P. K., \& Monteiro, P. J. (2006). Concrete: microstructure, properties, and materials. New York, NY: The McGraw-Hill Companies Inc.

Menzel, C. A. (1934). Strength and volume change of steamcured portland cement mortar and concrete. ACI Journal Proceedings, 31(11), 125-148.

Mindess, S., Young, J. F., \& Darwin, D. (1981). Concrete. Englewood Cliffs: Prentice-Hall.

Mostafa, N. Y., Shaltout, A. A., Omar, H., \& Abo-El-Enein, S. A. (2009). Hydrothermal synthesis and characterization of aluminium and sulfate substituted $1.1 \mathrm{~nm}$ tobermorites. Journal of Alloys and Compounds, 467(1), 332-337.

Murmu, M., \& Singh, S. P. (2014). Hydration products, morphology and microstructure of activated slag cement. International Journal of Concrete Structures and Materials, 8(1), 61-68.

Neville, A. M. (1973). Properties of concrete. London, UK: Pitman.

Oner, A., \& Akyuz, S. (2007). An experimental study on optimum usage of GGBS for the compressive strength of concrete. Cement \& Concrete Composites, 29(6), 505-514.

Saikia, N., Kato, S., \& Kojima, T. (2006). Thermogravimetric investigation on the chloride binding behaviour of MKlime paste. Thermochimica Acta, 444(1), 16-25.

Sanders, L. D., \& Smothers, W. J. (1957). Effect of tobermorite on the mechanical strength of autoclaved portland cementsilica mixtures*. ACI Journal Proceedings, 54(8), 127-139.

Shi, C., \& Hu, S. (2003). Cementitious properties of ladle slag fines under autoclave curing conditions. Cement and Concrete Research, 33(11), 1851-1856.

Singh, L. P., Goel, A., Bhattachharyya, S. K., Ahalawat, S., Sharma, U., \& Mishra, G. (2015). Effect of morphology and dispersibility of silica nanoparticles on the mechanical behaviour of cement mortar. International Journal of Concrete Structures and Materials, 9(2), 207-217. 
Taylor, H. F. W. (1997). Cement chemistry. London, UK: Telford Services Ltd.

Topçu, İ. B., \& Uygunoğlu, T. (2007). Properties of autoclaved lightweight aggregate concrete. Building and Environment, 42(12), 4108-4116.

Wee, T. H., Suryavanshi, A. K., \& Tin, S. S. (2000). Evaluation of rapid chloride permeability test (RCPT) results for concrete containing mineral admixtures. ACI Materials Journal, 97(2), 221-232.

Wongkeo, W., Thongsanitgarn, P., \& Chaipanich, A. (2012). Compressive strength and drying shrinkage of fly ashbottom ash-silica fume multi-blended cement mortars. Materials and Design, 36, 655-662.
Yang, Q., Zhang, S., Huang, S., \& He, Y. (2000). Effect of ground quartz sand on properties of high-strength concrete in the steam-autoclaved curing. Cement and Concrete Research, 30(12), 1993-1998.

Yazici, H. (2007). The effect of curing conditions on compressive strength of ultra high strength concrete with high volume mineral admixtures. Building and Environment, 42(5), 2083-2089.

Yazıcı, H., Yiğiter, H., Karabulut, A. Ş., \& Baradan, B. (2008). Utilization of fly ash and ground granulated blast furnace slag as an alternative silica source in reactive powder concrete. Fuel, 87(12), 2401-2407. 